\title{
EFFECT OF MEPERIDINE ON ADRENOCORTICAL FUNCTION IN MAN
}

\author{
Tsutomu Oyama, M.D., M. Takiguch, M.D., T. TAKazawa, M.D., \\ AND K. KIMURA, M.D."
}

THE EFFECTS of morphine on adrenocortical function in man have been studied by several workers. ${ }^{1-3}$ Although meperidine has been routinely employed in preoperative medication and as a postoperative analgesic agent, little has been published regarding its effect on adrenocortical function. Han and Brown reported that anaesthetic doses of meperidine supplemented by nitrous oxide inhibited the adrenocortical response to operation in six patients. Nitrous-oxideoxygen anaesthesia supplemented by meperidine is a useful balanced technique advocated by some. ${ }^{5-7}$ Recently we demonstrated that meperidine administered in combination with pentobarbital and atropine significantly decreased plasma cortisol levels in preoperative patients. ${ }^{8}$

The present study was undertaken to investigate the effect of meperidine alone and of meperidine-supplemented nitrous oxide anaesthesia on adreno. cortical function, as judged by their influence on free cortisol levels in the plasma in 30 patients undergoing operation.

\section{Merthods}

Thirty patients, ranging in age from 18 to 65 years, who were free from endocrine, hepatic, and renal disease, were the subjects of the study.

1. Nineteen patients were given meperidine $2 \mathrm{mg} / \mathrm{kg}$ intramuscularly at 7:30 AM and a blood sample was obtained at 8:30 AM just prior to the start of anaesthesia. The same patient's blood sample had been drawn at 8:30 AM on the day before operation, i.e. without meperidine, to serve as a control. Subjective emotional evaluation was made by asking whether the patient had fear or concerns about his operation. These questionnaires were employed just prior to induction of anaesthesia in the operating room.

2. Eleven patients who were scheduled for operation at 9:00 AM were given atropine $0.5 \mathrm{mg}$ intramuscularly 1 hour and 15 minutes prior to the induction of anaesthesia. Meperidine $100 \mathrm{mg}$ was diluted to $20 \mathrm{ml}$ in distilled water $(1 \mathrm{ml}=$ $5 \mathrm{mg}$ ). Anaesthesia was induced at 8:30 AM after the first blood sampling, by intermittent intravenous administration of meperidine $25 \mathrm{mg}$ supplemented with $\mathrm{N}_{2} \mathrm{O}(3.5 \mathrm{~L} / \mathrm{min})$ and $\mathrm{O}_{2}(1.5 \mathrm{~L} / \mathrm{min})$. Succinylcholine chloride $40 \mathrm{mg}$ was given intravenously to provide muscle relaxation sufficient for endotracheal intubation. Induction of anaesthesia required 8 to 12 minutes, and $50-250 \mathrm{mg}$ (mean $120 \mathrm{mg}$ ) of meperidine was used. General anaesthesia was maintained with nitrous oxide at a flow of $3.5 \mathrm{~L} / \mathrm{min}$ and oxygen at a flow of $1.5 \mathrm{~L} / \mathrm{min}$. Subsequent doses of

'Department of Anesthesiology, Hirosaki University School of Medicine, Hirosaki, AomoriKen, Japan. 
meperidine $25 \mathrm{mg}(5 \mathrm{ml}$ ) were injected intravenously when needed, and an average total of $336 \mathrm{mg}(120-615 \mathrm{mg}$ ) was employed. The respiration was assisted or controlled, and curare was used as required to provide muscle relaxation for abdominal cases ( $21-30 \mathrm{mg}$ ).

Table I shows the surgical procedures included in the study, average durations of anaesthesia, and total meperidine used. The mean operating time was 2 hours and 34 minutes, and the average anaesthesia time was 3 hours and 54 minutes. The mean blood loss was $550 \mathrm{ml}$ and low molecular weight dextran (Rheomacrodex $500 \mathrm{ml}$ was infused during the procedure. Blood transfusion was used to replace blood loss over $500 \mathrm{ml}$. No appreciable cardiovascular depression was found, judged by the arterial blood pressure and electrocardiographic observation during anaesthesia. The depth of anaesthesia was monitored by EEG, and arterial blood gas analyses were done by the Astrup method in a few cases. We could find evidence of neither anoxia nor hypercarbia in these patients.

TABLE I

Patients Studied and Operations Performed

\begin{tabular}{ccclccc}
\hline $\begin{array}{c}\text { Case } \\
\text { no. }\end{array}$ & Age & Sex & Surgery performed & $\begin{array}{c}\text { Duration } \\
\text { of operation } \\
\text { (hrs) }\end{array}$ & $\begin{array}{c}\text { Duration } \\
\text { of anaes. } \\
\text { (hrs) }\end{array}$ & $\begin{array}{c}\text { Total } \\
\text { meperidine } \\
\text { (mg) }\end{array}$ \\
\hline 1 & 29 & F & Cholecystectomy & 2.00 & 4.00 & 315 \\
2 & 62 & F & Removal of bone nail & 0.20 & 1.30 & 120 \\
3 & 45 & F & Cholecystectomy & 4.15 & 5.15 & 305 \\
4 & 50 & F & Hysterectomy & 1.05 & 2.15 & 220 \\
5 & 59 & F & Hysterectomy & 3.20 & 4.50 & 260 \\
6 & 45 & F & Hysterectomy & 2.15 & 3.00 & 335 \\
7 & 46 & M & Gastrectomy & 2.05 & 3.25 & 394 \\
8 & 47 & F & Hysterectomy & 3.55 & 5.35 & 486 \\
9 & 51 & F & Gastrectomy & 4.10 & 6.50 & 615 \\
10 & 48 & F & Hysterectomy & 2.20 & 2.55 & 315 \\
11 & 40 & F & Mastectomy & 2.30 & 3.20 & 329 \\
Mean & & & & 2.34 & 3.54 & 336 \\
\hline
\end{tabular}

The blood sampling times were as follows: (1) 8:30 AM just prior to induction; (2) 30 minutes after anaesthesia alone; (3) 30 minutes, 1 hour, and 2 hours after the start of operation; (4) when the patient had fully awakened in the recovery room. Three millilitres of venous blood were obtained in a heparinized syringe, and centrifuged within 30 minutes. The free cortisol (17-hydroxycorticosteroid $=17$-oHcs $=$ hydrocortisone $)$ in $1 \mathrm{ml}$ of plasma was determined according to the method of Rudd, ${ }^{9}$ with a Farrand spectrofluorometer. The duplicate error of our method was $\pm 1.2 \mu \mathrm{g}$ per $100 \mathrm{ml}$ of plasma, which appeared to be reliable for the analysis of our data.

\section{Results}

1. Table II shows the effect of meperidine alone as premedication on plasma free cortisol levels. The average plasma free cortisol levels at 8:30 AM just prior to induction on the day of operation in 19 patients who were given meperidine 
TABLE II

Effect of Meperidine ( $2 \mathrm{mg} / \mathrm{kg}$ ) on Plasma Free Cortisol Levels in Man ( $\mu \mathrm{g} / 100 \mathrm{ml}$ )

\begin{tabular}{ccc}
\hline $\begin{array}{c}\text { Case } \\
\text { no. }\end{array}$ & Preoperative day & Day of surgery \\
\hline 1 & 10.0 & 16.0 \\
2 & 9.0 & 11.0 \\
3 & 13.5 & 20.0 \\
4 & 11.0 & 22.0 \\
5 & 13.5 & 24.0 \\
6 & 24.0 & 22.0 \\
7 & 13.0 & 14.0 \\
8 & 22.0 & 10.0 \\
9 & 16.0 & 22.0 \\
10 & 10.0 & 11.0 \\
11 & 18.5 & 25.0 \\
12 & 13.0 & 23.0 \\
13 & 24.0 & 16.0 \\
14 & 11.5 & 17.0 \\
15 & 17.0 & 30.0 \\
16 & 14.0 & 20.0 \\
17 & 14.0 & 24.0 \\
18 & 16.0 & 21.0 \\
19 & 17.0 & 28.0 \\
Mean & 15.1 & 19.8 \\
SE & \pm 1.0 & $\pm 1.3^{*}$ \\
\hline$* t=3.13, p<0.01$. & \\
\hline \multirow{*}{*}{$*$} & &
\end{tabular}

TABLE III

Plasma Free $17-\mathrm{OHCS}$ Levels during Meperidine- $\mathrm{N}_{2} \mathrm{O}$ Anaesthesia and Surgery

\begin{tabular}{|c|c|c|c|c|c|c|}
\hline \multirow[b]{2}{*}{$\begin{array}{l}\text { Case } \\
\text { no. }\end{array}$} & \multicolumn{6}{|c|}{ Plasma Free 17-OHCS Levels $(\mu \mathrm{g} / \mathrm{dl})$} \\
\hline & Preind. & $\begin{array}{l}\text { Postanaes. } \\
30 \mathrm{~min} \text {. }\end{array}$ & $\begin{array}{l}\text { Postop. } \\
30 \text { min. }\end{array}$ & $\begin{array}{l}\text { Postop. } \\
60 \text { min. }\end{array}$ & $\begin{array}{l}\text { Postop. } \\
120 \text { min. }\end{array}$ & $\begin{array}{c}\text { Recovery } \\
\text { room }\end{array}$ \\
\hline 1 & 22.0 & 12.0 & - & 13.0 & - & 18.0 \\
\hline 2 & 12.0 & 16.0 & 27.0 & - & - & 28.0 \\
\hline 3 & 13.7 & 13.7 & 17.5 & 30.0 & 26.0 & 34.0 \\
\hline 4 & 21.2 & 14.3 & 37.0 & 38.5 & - & 40.0 \\
\hline 5 & 12.5 & 17.0 & 12.0 & 18.0 & 12.0 & 18.0 \\
\hline 6 & 17.0 & 10.0 & 10.0 & 16.0 & 13.0 & 15.0 \\
\hline 7 & 10.0 & 11.0 & 17.0 & 20.0 & 26.0 & 27.0 \\
\hline 8 & 17.0 & 23.0 & 16.0 & 23.0 & 27.0 & 24.0 \\
\hline 9 & 18.7 & 18.7 & 17.5 & 23.8 & $22 . \overline{5}$ & 20.0 \\
\hline 10 & 16.0 & 18.0 & 18.0 & 22.0 & 22.0 & 18.0 \\
\hline 11 & 16.0 & 15.0 & 18.0 & - & - & 16.0 \\
\hline Mean & 16.0 & 15.3 & 19.0 & 22.7 & 21.6 & 23.5 \\
\hline SE & 1.13 & 1.13 & 2.45 & 2.56 & 1.74 & 2.76 \\
\hline$p^{*}$ & & NS & NS & $<0.0 \overline{5}$ & NS & $<0.02$ \\
\hline
\end{tabular}

*Mean levels were compared with preinduction values. $\mathrm{SE}=$ Standard error.

NS $=$ Statistically not significant. 
$(2 \mathrm{mg} / \mathrm{kg}$ ) one hour before was $19.8 \pm 1.3 \mu \mathrm{g}$ per $100 \mathrm{ml}$ of plasma ( $\pm=$ standard error of the mean). The mean value in the same patients without meperidine at a similar time on the day preceding operation was $15.1 \pm 1.0 \mu \mathrm{g}$. The difference between these mean values was statistically significant $(p<0.01)$. Ten $(52 \%)$ of the 19 subjects who received meperidine did not feel apprehension in the operating room, and 6 patients (31\%) felt a little drowsy.

2. The mean plasma free cortisol levels at 8:30 AM on the day of operation in 11 control patients who received atropine only was $16.0 \pm 1.1 \mu \mathrm{g}$. It decreased slightly but insignificantly $(0.7 \mu \mathrm{g})$ at 30 minutes after anaesthesia alone. The plasma free cortisol level increased gradually and rose significantly to $22.7 \pm$ $2.5 \mu \mathrm{g}(p<0.05) 60$ minutes after the start of the operation. It further increased to $23.5 \pm 2.7 \mu \mathrm{g}(p<0.02)$ in the recovery room when the patients were considered to have fully awakened, as shown in the Table III and Figure 1.

3. Case report: In a 47-year-old woman who underwent hysterectomy for prolapsus uteri, $200 \mathrm{mg}$ meperidine was used for induction and $286 \mathrm{mg}$ more were added for maintenance. The operating time was 3 hours and 55 minutes. The plasma free cortisol level rose from $17.0 \mu \mathrm{g}$ to $23.0 \mu \mathrm{g}$ after 30 minutes of

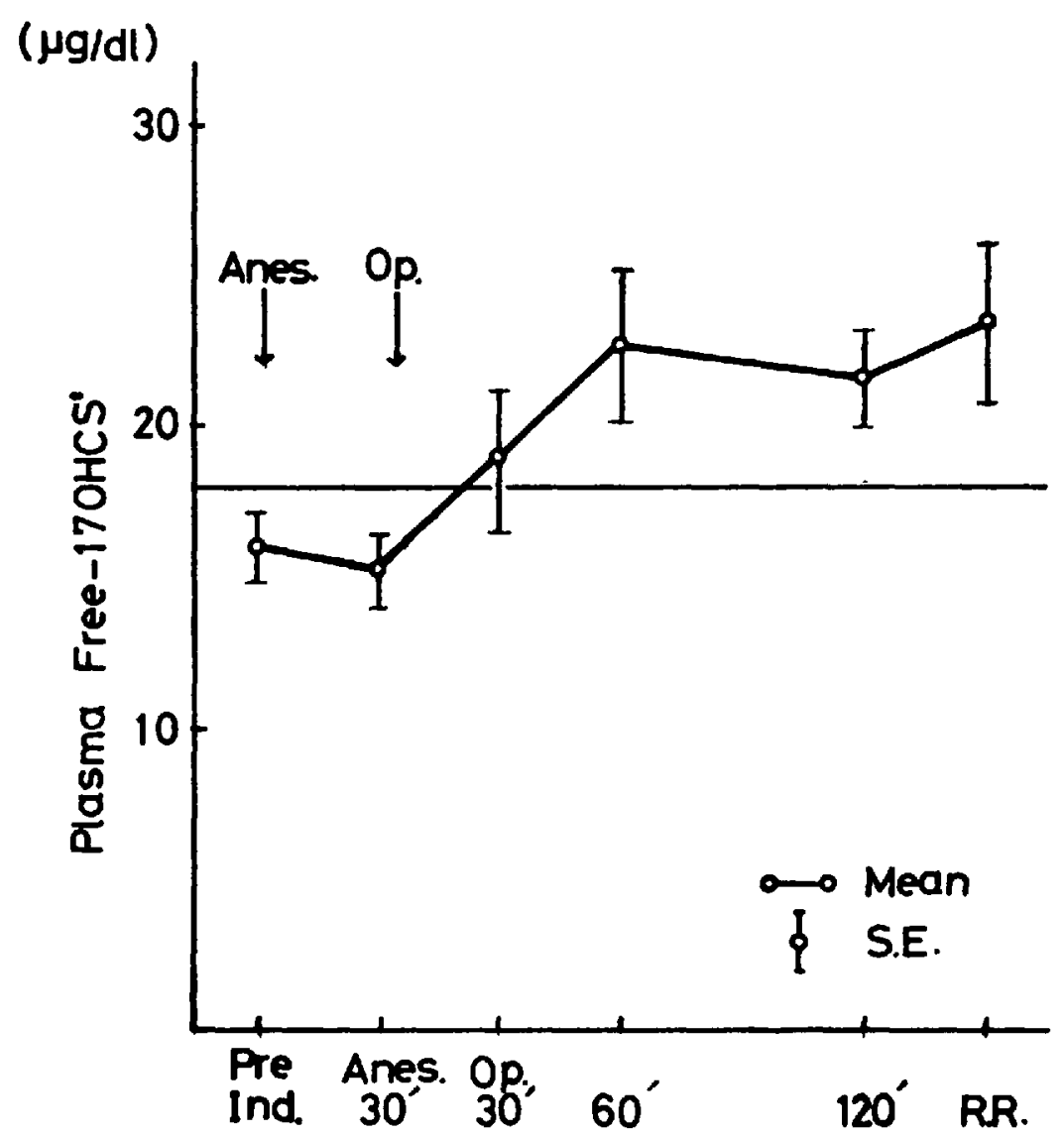

Figure 1. Plasma free 17-oHcs levels during meperidine- $\mathrm{N}_{2} \mathrm{O}$ anaesthesia and surgery. 


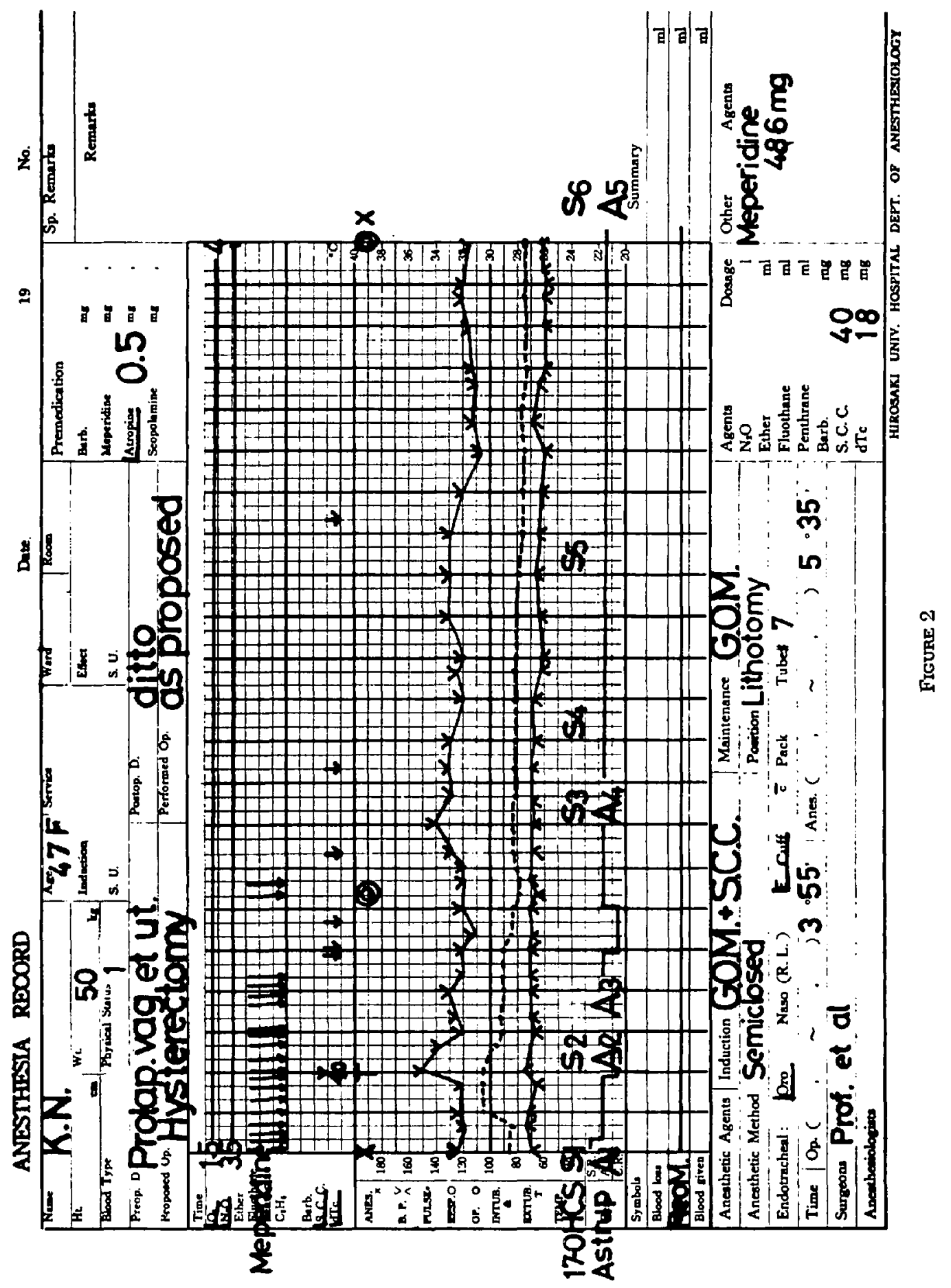




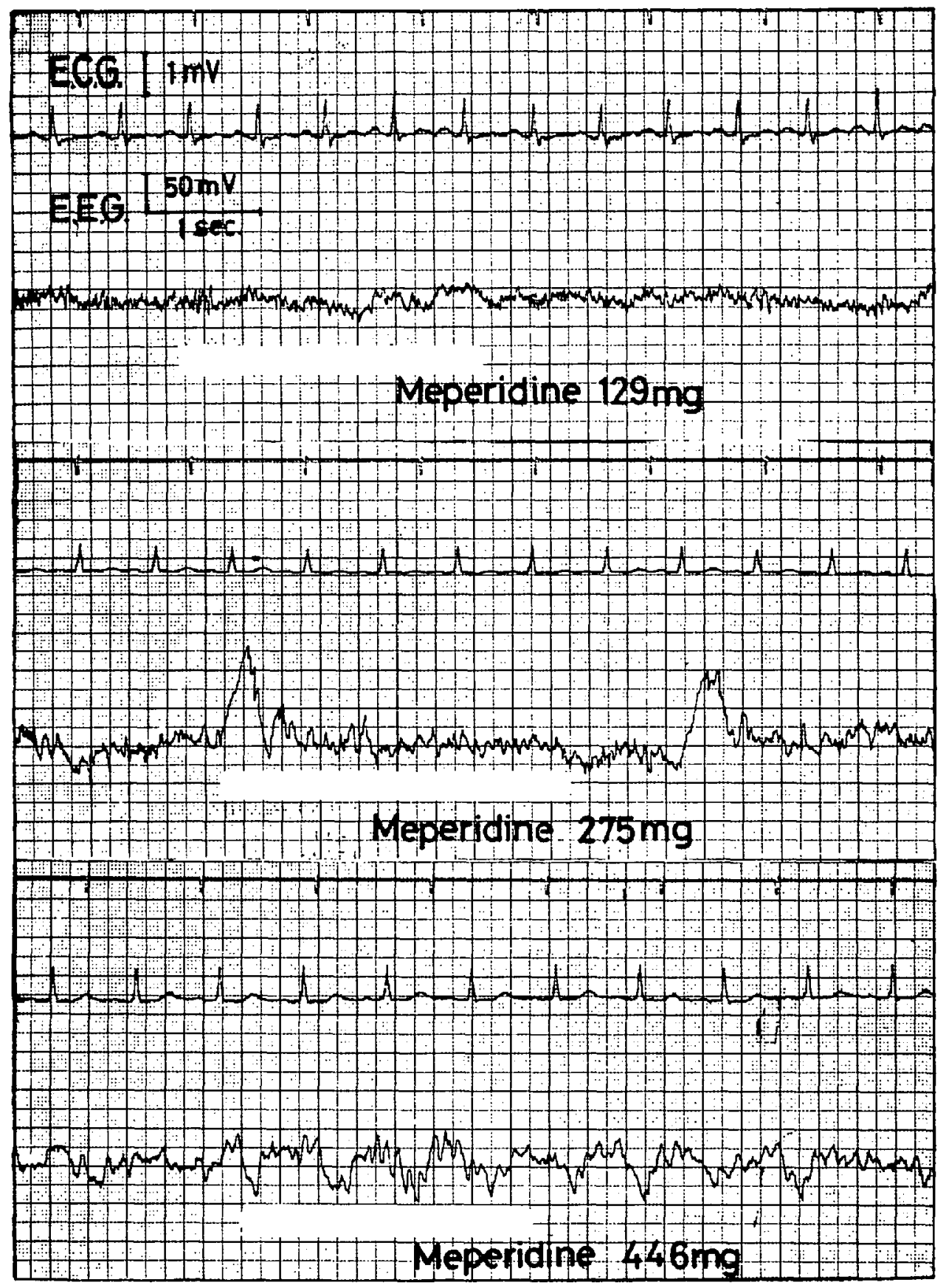

FIGURE 3. ECG and EEG during meperidine- $\mathrm{N}_{2} \mathrm{O}$ anaesthesia. 
anaesthesia. Two hours after the start of the operation it increased further to $27.0 \mu \mathrm{g}$ (Fig. 2). No marked alteration in blood pressure or electrocardiographic findings was observed as shown in Fig. 3. No evidence of anoxia or hypercarbia was found in this case as shown in Table IV, and the EEG pattern was similar to that reported by Brechner et al. ${ }^{10}$

TABLE IV

Acid-Base Balance during Meperidine- $\mathrm{N}_{2} \mathrm{O}$ Anaesthesia

\begin{tabular}{|c|c|c|c|c|c|c|c|c|}
\hline $\begin{array}{l}\text { Sample } \\
\text { no. }\end{array}$ & $\begin{array}{l}\text { Body } \\
\text { temp. } \\
\left({ }^{\circ} \mathrm{C}\right)\end{array}$ & $\mathrm{pH}$ & $\begin{array}{c}\mathrm{PCO}_{2} \\
(\mathrm{~mm} \mathrm{Hg})\end{array}$ & $\begin{array}{c}\mathrm{Po}_{2} \\
(\mathrm{~mm} \mathrm{Hg})\end{array}$ & $\mathrm{BE}$ & $\underset{\left(\mathrm{mEq} / \mathrm{L}_{-}\right)}{\mathrm{HCO}_{8}}$ & $\begin{array}{l}\text { Hct } \\
(\%)\end{array}$ & $\begin{array}{c}\mathrm{Hb} \\
(\mathrm{gm} / \mathrm{dl})\end{array}$ \\
\hline$A_{1}$ & 37.3 & 7.46 & 25.9 & 55.0 & -4.3 & 18.0 & 30 & 10.0 \\
\hline $\mathrm{A}_{2}$ & 37.1 & 7.42 & 34.1 & 171.0 & -2.0 & 21.5 & 31 & 10.3 \\
\hline$A_{8}$ & 37.1 & 7.51 & 23.5 & 127.1 & -2.8 & 18.6 & 30 & 10.0 \\
\hline$A_{4}$ & 37.1 & 7.51 & 27.4 & 133.0 & -0.2 & 21.5 & 32 & 10.6 \\
\hline$A_{5}$ & 36.5 & 7.40 & 32.9 & 171.9 & -3.5 & 20.0 & 34 & 11.3 \\
\hline
\end{tabular}

\section{Discussion}

Previously we reported that preoperative apprehension elicits adrenocortical stimulation, as judged by the elevation of the plasma free cortisol level, and that meperidine combined with pentobarbital and atropine significantly depress it in preoperative patients. $^{8}$ Furthermore, we found that pentobarbital ${ }^{11}$ and tranquillizers such as diazepam and nitrazepam ${ }^{12}$ significantly reduce preoperative adrenocortical excitability. The average plasma free cortisol level at 8:30 AM on the day preceding operation, when the patients are free from stress, is about $14.0 \mu \mathrm{g}$. We found that it increases to $20.5 \mu \mathrm{g}$ in the same patients without any premedication at a similar time on the day of operation. ${ }^{8,11,12}$ This is similar to the level in meperidine-treated patients, and suggests that the sedative effect of meperidine is inadequate to alleviate preoperative apprehension as judged by its adrenocortical influence.

There has been some question as to the need for, or advisability of, the routine use of any narcotic as a preanaesthetic medication in pain-free patients. ${ }^{13,14}$ Cohen and Beecher ${ }^{13}$ reported that morphine $(15 \mathrm{mg} / 70 \mathrm{~kg}$ body weight) did not much reduce the proportion of patients who were apprehensive before operation. Eckenhoff and Helrich ${ }^{14}$ observed that secobarbital led to a higher proportion of calm, carefree patients than did morphine and meperidine. Meperidine with atropine was reported by Feldman ${ }^{15}$ to be little better than hyoscine alone in allaying anxiety before operation. Our subjective evaluation of meperidine demonstrated that $52 \%$ of the patients appeared to be free from apprehension. This magnitude of effect in calming apprehension is similar to that of hydroxyzine (Atarax) in our previous study, ${ }^{12}$ which did not significantly depress the plasma free cortisol level at 8:30 AM on the day of operation, whereas pentobarbital $(2 \mathrm{mg} / \mathrm{kg})$ had more sedative effect $(78 \%)$ than meperidine and significantly reduced the plasma cortisol level. ${ }^{11}$ Therefore, the mild sedative effect of meperidine, as evaluated subjectively, correlated well with its failure to inhibit adrenocortical activity in the preoperative patients. 
Siker et al. ${ }^{2}$ reported that morphine $0.15 \mathrm{mg} / \mathrm{kg}$, administered intravenously, reduced plasma free cortisol levels, but it was a statistically insignificant reduction in 16 preoperative patients. Fraser et al. ${ }^{3}$ observed no consistent change in urinary 17-oHCs excretion following the acute administration of morphine (average of $75 \mathrm{mg} /$ day for three successive days). McDonald et al. ${ }^{1}$ reported that morphine $16 \mathrm{mg}$ injected subcutaneously in sedated normal subjects significantly depressed plasma hydrocortisone levels. But morphine given alone or in combination with barbiturate and parasympatholytic agents in doses for preanaesthetic medication has been reported to have no effect on plasma free cortisol levels. ${ }^{6-18}$ The neglect of diurnal variation in the plasma free cortisol levels seems to account for the discrepancy between other findings and our own reports. ${ }^{11.12}$ Nevertheless our findings accord with others on the point that this combination of premedicants does not significantly inhibit the adrenocortical response to surgery.

The use of intravenous meperidine to supplement nitrous oxide and oxygen is a technique of balanced anaesthesia. We have demonstrated that this combination could not inhibit adrenocortical stimulation by surgical stress. This differs from the report of Han and Brown. ${ }^{4}$ According to them, the average preinduction plasma free cortisol value was $30.3 \pm 3.8 \mu \mathrm{g}, 25.9 \pm 3.1 \mu \mathrm{g}$ during anaesthesia alone, $29.1 \pm 5.3 \mu \mathrm{g}$ during operation, and $37.5 \pm 1.1 \mu \mathrm{g}$ one to two hours postoperatively. However, these data were not analysed statistically, and with surgical intervention only three of the six patients showed small declines in the plasma cortisol levels. Meperidine was used by them as it was used in our study.

An increase in plasma cortisol levels has been shown during operation under general anaesthetic techniques. ${ }^{16-21}$ Some anaesthetic agents such as ether, cyclopropane, gamma-hydroxybutyrate, and halothane cause a rise before the operation is started..$_{1}^{810-20}$ On the other hand, thiopental and methoxyflurane have been reported to have the least stimulating effect on adrenocortical activity. ${ }^{16-19,21}$ When neural pathways from the surgical area are blocked by spinal anaesthesia or hypothermia, an elevation in plasma cortisol does not occur. ${ }^{16-19}$ Some workers have suggested that meperidine exerts its blocking action on the stress reaction in the pituitary through the central nervous system.10 Despite the slight decrease in plasma cortisol levels observed during meperidine-nitrous-oxide anaesthesia, the stimulation of the adrenal cortex was not blocked by this technique during operation.

From the clinical point of view, this technique possesses desirable features such as rapid and quiet postoperative recovery, prolonged postoperative analgesia, and nonflammability. Its disadvantages are variable degrees of respiratory depression which necessitate continuous assistance or control of respiration, and slow induction of anaesthesia in comparison with thiopental. It may result in histamine liberation, which occasionally causes whealing along the course of the injected vein. The anaesthetist must be familiar with the signs which indicate the necessity for additional doses of meperidine in order to avoid movement of extremities, straining, and coughing. Arterial hypotension was seldom observed in our series. 


\section{Summary and Conclusions}

The present study was undertaken to evaluate the effect of meperidine alone and of meperidine-supplemented nitrous oxide anaesthesia on adrenocortical function, as judged by their influence on plasma free cortisol levels in 30 patients undergoing operation. In conformity with its relatively insufficient sedative effect, meperidine administered intramuscularly $(2 \mathrm{mg} / \mathrm{kg}$ ) one hour prior to induction of anaesthesia did not inhibit adrenocortical stimulation due to emotional stress. Meperidine-nitrous-oxide anaesthesia alone for 30 minutes did not stimulate adrenocortical activity, but could not block adrenocortical stimulation during surgical intervention and after operation.

\section{RÉSUMÉ}

La présente étude a été entreprise pour évaluer l'effet de la mépéridine seule ou de l'anesthésie au protoxyde d'azote additionné de mépéridine sur la fonction cortico-surrénalienne selon leur influence sur les niveaux de cortisol libre de plasma, chez 30 sujets subissant une opération. Conformément à son effet sédatif relativement insuffisant, la mépéridine administrée par voie intra-musculaire $(2 \mathrm{mg} / \mathrm{kg})$ une heure avant l'induction de l'anesthésie n'a pas empêché la stimulation cortico-surrénalienne due au stress émotionnel. L'anesthésie seule au protoxyde d'azote-mépéridine durant 30 minutes n’a pas stimulé l'activité adréno-corticale, mais elle n'a pas pu bloquer la stimulation adréno-corticale pendant et après l'opération.

\section{REFERENCES}

1. McDonald, R. K.; Evans, F. T.; Weise, V. K.; \& Patrick, R. W. Effect of Morphine and Nalorphine on Plasma Hydrocortisone Levels in Man. J. Pharmacol. Exper. Therap. 125: 241 (1959).

2. SinEr, E. S.; Lipschirz, E.; \& KLEIN, R. The Effect of Preanesthetic Medications on the Blood Level of 17-Hydroxycorticosteroids. Ann. Surg. 143: 89 (1956).

3. Fraser, H. F.; Eisenman, A. J.; \& Brooks, J. W. Urinary Excretion of 5hIAA and Corticoids after Morphine, Meperidine, Nalorphine, Reserpine and Chlorpromazine. Fed. Proc. 16: 298 (1957).

4. Han, Y. H. \& Brown, E. S. Pituitary Blockade by Meperidine in Man. Anesthesiology. 22: 909 (1961).

5. Brotman, M.; Cullen, S. C.; \& WrikiNs, D. S. Intravenous Supplementation during Nitrous Oxide Anesthesia: Comparison of Demerol, Morphine and a New Potent Analgesic Drug (15431). Anesthesiology. 11: 527 (1950).

6. Auld, W. Pethidine, Curare, Nitrous Oxide-Oxygen Anaesthesia in Children. Anaesthesia. 7: 161 (1952).

7. Ausherman, H. A.; Nowirl, W. K.; \& Stephen, C. R. Controlled Analgesia with Continuous Drip Meperidine: Analysis of 1000 Cases. J.A.M.A. 160: 175 (1956).

8. Oyama, T.; Shubata, S.; Matsumoto, F.; Takiguchu, M.; \& Kudo, T. Effects of Halothane Anaesthesia and Surgery on Adrenocortical Function in Man. Canad. Anaesth. Soc. J. 15: 258 (1968).

9. Rudp, B. T.; Cowper, J. M.; \& Crawfond, N. The Determination of Plasma Free Hydrocortisone and Corticosterone by a Combined Fluorimetric and Modified PorterSilber Procedure. Clin. Chim. Acta. 6: 686 (1981).

10. Brechner, V. L.; Walter, R. D.; \& Drllon, J. B. Practical Electroencephalography for Anesthesiologist. Springfield, Ill.: Charles C. Thomas (1962). 
11. Oyama, T.; Shibata, S.; Kmmra, K.; \& Takazawa, T. An Objective Evaluation of Pentobarbital as Preanesthetic Medication: Effect on Adrenocortical Function. Anesth. \& Analg. 47: 48 (in press 1969).

12. Oyama, T.; Kimura, K.; Takazawa, T.; \& Takiguchi, H. An Objective Evaluation of Tranquillizers as Preanaesthetic Medication: Effect on Adrenocortical Function. Canad. Anaesth. Soc. J. 16: 209 (1969).

13. COHEN, E. N. \& BEecher, H. K. Narcotics in Preanesthetic Medication: Controlled Study, Report to Council on Pharmacy and Chemistry. J.A.M.A. 147: 1664 (1951).

14. Eckenhoff, J. E. \& Helrich, M. Study of Narcotics and Sedatives for Use in Preanesthetic Medication. J.A.M.A. 167: 415 (1958).

15. Feldman, S. A. A Comparative Study of Four Premedications. Anaesthesia. 18: 169 (1963).

16. Hammond, W. G.; Vandam, L. D.; Davis, J. M.; Carter, R. D.; Ball, M. R., \& Moore, F. D. Studies in Surgical Endocrinology: IV. Anesthetic Agents as Stimuli to Change in Corticosteroids and Metabolism. Ann. Surg. 148: 199 (1958).

17. Virtue, R. W.; Helmach, M. L.; \& Gainza, E. Adrenal Cortical Response to Surgery: I. The Effect of Anesthesia on Plasma 17-Hydroxycorticosteroid Levels. Surgery. 41: 549 (1957).

18. VANDAM, L. D. \& Moore, F. D. Adrenocortical Mechanisms Related to Anesthesia. Anesthesiology. 21: 531 (1960).

19. Van Brunt, E. E. \& Ganong, W. F. The Effects of Preanesthetic Medication, Anesthesia and Hypothermia on Endocrine Effects. Anesthesiology. 24: 543 (1963).

20. Oyama, T. et al. Effects of $\gamma$-Hydroxybutyrate on Plasma Hydrocortisone Concentration in Man. Anesth. \& Analg. $47: 350$ (1968).

21. Oyama, T.; Shibata, S.; Matsumoto, F.; Matsukt, A.; Kmmura, K.; Takazawa, T.; \& Kuno, T. Adrenocortical Function Related to Methoxyflurane Anesthesia and Surgery in Man. Canad. Anaesth. Soc. J. 15: 362 (1968). 